\title{
Walter Benjamin. A política do tradutor
}

\author{
Helano Ribeiro ${ }^{1}$ \\ Universidade Federal da Paraíba - UFPB, João Pessoa, Paraíba, Brasil
}

\begin{abstract}
Resumo: Este artigo propõe uma articulação crítica acerca texto de Walter Benjamin "A tarefa do tradutor" a partir de uma ideia que ele nos coloca: tradução e messianismo, forças de um por vir da vida e história, são de ordem politicamente ética, mas também de transgressão e profanação. A política do tradutor, assim, se apresenta através de suas decisões tradutórias e resulta em um processo de contaminação da obra original e sua tradução. Esse gesto pressupõe um encontro de hospitalidade incondicional. A intrusão do original na língua de tradução é um movimento de pura alteridade. A partir de Giorgio Agamben, temos a tarefa do tradutor como um ato de profanação. Jacques Derrida e Jean-Luc Nancy embasam a discussão teórica acerca da hospitalidade absoluta e da intrusão inerente à própria vida, intrínseca à tarefa política do tradutor.
\end{abstract}

Palavras-chave: Walter Benjamin; Tradução; Hospitalidade; Política.

Title: Walter Benjamin. The translator's policy

Abstract: This article proposes a critical articulation about Walter Benjamin's text "The task of the translator" based on an idea that he puts to us: translation and messianism, forces of one to come from life and history, are of a politically ethical order, but also of a transgression and profanation nature. The translator's policy, therefore, presents itself through his translation decisions and results in a process of contamination of the original work and its translation. This gesture presupposes an encounter of unconditional hospitality. The intrusion of the original into the language of translation is a movement of pure otherness. From Giorgio Agamben, we have the task of the translator as an act of profanation. Jacques Derrida and Jean-Luc Nancy support the theoretical discussion about absolute hospitality and the intrusion inherent in life itself, intrinsic to the translator's political task.

Keywords: Walter Benjamin; Translation; Hospitality; Policy.

\section{O próprio e o estranho: a utopia da hospitalidade}

Walter Benjamin, em seu conhecido texto de 1923 "A tarefa do tradutor", nos propõe a ideia de que o tradutor, em posição ambígua, executa sua função de modo deficiente, submetido a duas verdades: ele deve validar a lei do estranho e a sua própria e, em um contundente dilema, transgredir, mas também, simultaneamente, afetar um em

\footnotetext{
${ }^{1}$ Doutor em Literatura pela Universidade Federal de Santa Catarina - UFSC. Professor Adjunto do Departamento de Mediações Interculturais - UFPB. Líder do Grupo de Pesquisa do CNPq Walter Benjamin: fantasma, imago, espectro. Orcid: https://orcid.org/0000-0003-0192-0397 E-mail: hjcribeiro@gmail.com
} 
conformidade com o outro. A tradução expõe, em seu gestualidade, igualmente, a vulnerabilidade do estranho, assegurando-Ihe sua pervivência, ela aponta de imediato para sua contaminação: "na sua "pervivência [grifo meu]" (que não mereceria tal nome, se não fosse transformação e renovação de tudo aquilo que vive), o original se modifica [grifo meu]." (BENJAMIN, 2011, p. 107). Nesse contato, o hiato que distancia tradução e suposto original é incorporado nele próprio. De igual modo, a tradução profanadora, regida pela pulsão de vida desse estranho em vias de extinção, devém amorosa fonte de luz vital. Ela é o signo doador de sobrevida do original [Fortleben], até mesmo o shibboleth - palavrapasse das passagens do tempo para história, via de acesso do estranho ao novo território, lugar de encontro da hospitalidade incondicional. A tradução segue, ainda, na concepção benjaminiana, a densidade da complexa tessitura entre vida, linguagem e história; operando como impronta, rastro do tempo que resta, insistência da presença do insólito. Ela se apresenta em sua possibilidade utópica. E não pensemos que a vida enquanto categoria seja apenas um apelo ao orgânico, a vida pertence à história ou, melhor, a uma forma impetuosa de historicidade, seu fluxo se dá na correnteza da linguagem.

No Livro de Gênesis, capítulo onze, sétimo versículo, encontramos, por um lado, o vocábulo balal, denotando o sentido de abalo, confusão e mistura da linguagem única do povo determinado a construir uma torre que os levasse ao céu. Por outra lado, o termo baal provavelmente mais antigo que Babel, significa deus, senhor. Então o ressentimento divino determinou um castigo para os homens ao fragmentar as línguas e reestabelecer o Seu nome e a ordem: a imposição do gesto tradutório como uma necessidade para o entendimento humano através do seu paradoxal interdito. A tradução seria o resultado de uma certa reconciliação, revelada em sua necessária possibilidade utópica e transgressora².

Benjamin, ao investigar o processo tradutório nessas fissuras da interdição divina, apresenta o tradutor e sua tarefa profanatória, alguém impossibilitado de verter em sua língua o conteúdo idêntico da ilusória sacralidade do original, mas que ainda o executa. A tradução, consequentemente, toca o estranho sagrado e o lança ao uso comum dos homens. Nesse ato deambulante, no entanto generoso, ela profana o original. Nas palavras de Giorgio Agamben: "Puro, profano, livre dos nomes sagrados [grifo meu], é o que é restituído ao uso comum dos homens. Mas o uso aqui não aparece como algo natural; aliás, só se tem acesso ao mesmo através de uma profanação." (AGAMBEN, 2007, p. 65) e continua: "Profanar não significa simplesmente abolir e cancelar as separações, mas aprender a fazer delas um uso novo, a brincar com elas." (AGAMBEN, 2007, p. 75). Isso equivale, para o tradutor, a uma busca por esse Spiel [jogo, brincadeira], aqui entendido por processo tradutório. Talvez seja um possível entendimento do que Benjamin denomina de Spielraum espaço do jogo ou Medium de inoperância da Lei, o que nos anuncia a tarefa do tradutor, sobretudo, como um gesto político, a partir dessa mesma utópica possibilidade profanadora e inoperante.

A tarefa do tradutor se evidencia em sua busca infante, ou seja, o rápido fazer e des-

\footnotetext{
2 Importante salientar aqui que pretendo fugir da dicotomia possibilidade $\mathrm{x}$ impossibilidade da tradução, ao permanecer na ideia que defendo de possibilidade utópica.
} 
fazer através do jogo, a convivência com o estranho não para tomá-lo como seu igual, mas para viver ao seu lado, recriar o dizível ao lado do in-dizível. Desmontar o brinquedo, despedaçando-o, eis a tarefa do tradutor: as pequenas peças surgem pouco a pouco através do jogo disseminatório de sentidos. Os cacos, outrora ocultos pela forma do estranho, fazem surgir outros ritmos. Esse é seu pequeno jogo, ou tentativa de desconstrução da estrutura, da linguagem do homem em geral. A tradução torna-se a atividade profanadora de libertação do sagrado [sacer] para o uso comum, o que também implica em sua própria dessacralização.

Esse gesto político e redentor do tradutor, no entanto, não se dá na oposição de diferenças entre as línguas, mas sim, no seu caráter complementar; elas estão juntas numa espécie de simbiose a ser alcançada, uma esperança tácita que Benjamin chamará de pura língua, uma língua maior por vir. O tradutor possui, diante de si, uma tarefa messiânica: juntar os fragmentos, cacos de um vaso quebrado - Schebira ${ }^{3}$ - que devem permanecer reunidos para alcançar a pura língua por vir [kommend]:

Da mesma forma como os cacos de um vaso, para serem recompostos, devem encaixar-se uns aos outros nos mínimos detalhes, mas sem serem iguais, a tradução deve, ao invés de procurar dessemelhar-se ao sentido do original, conformar-se amorosamente, e nos mínimos detalhes, em sua própria língua, ao modo de visar do original, fazendo com que ambos sejam reconhecidos como fragmentos de uma língua maior, como cacos são fragmentos de um vaso. (BENJAMIN, 2011, p. 115).

A pura língua vindoura, com isso, surgirá não na velocidade devoradora de Chrónos, mas sim, através da suspensão redentora e utópica do tempo messiânico. Jacques Derrida expõe em Torres de Babel que:

\begin{abstract}
Graças à tradução, dito de outra forma, a essa suplementaridade linguística pela qual uma língua dá a outra o que lhe falta, e lho dá harmoniosamente, esse cruzamento das línguas assegura o crescimento das línguas, e mesmo esse "santo crescimento das línguas" "até o termo messiânico da história". Tudo isso se anuncia no processo tradutor, através da "eterna sobrevida das obras" ou o "renascimento infinito das línguas". Essa perpétua revivescência, essa regeneração constante pela tradução, é menos uma revelação, a revelação ela mesma, que uma anunciação, uma aliança e uma promessa. (DERRIDA, 2002, p. 67-68).
\end{abstract}

A suplementaridade deslinda uma adição, um significante livre que deve ser acrescentado a outro para o complemento da falta de uma significação, movendo através desse mesmo deslocamento à doação do excesso faltante. O suplemento só existe, porque dissolve a lógica de uma origem e de um desenvolvimento [Entwicklung], leia-se aqui na teoria de Benjamin a origem/ o original - Ursprung - ou salto anacrônico [Sprung] a uma coisa primeva [ur] - e um fim [télos] representado pela história teleológica dos vencedores.

\footnotetext{
${ }^{3}$ Vaso que deveria guardar a luz desprendida por Deus, mas que não resistiu devido ao poder dessa profusão. Desde a criação Divina.
} 
Apenas dessa forma, é possível pensarmos na movimentação do jogo de substituições da linguagem. A partir da lógica do suplemento, em cada fazer tradutório, o contato entre línguas as leva até a direção da língua por vir, da pura língua. Essa é, indubitavelmente, a utópica tarefa do tradutor de Walter Benjamin.

Talvez o poema "Salto" de Orides Fontela, retirado do livro Transposição, possa nos dimensionar essa mesma possibilidade utópica enquanto atribuição do tradutor: um lugar ideal, inabitável, mas ainda assim o topos de uma possibilidade do por vir.

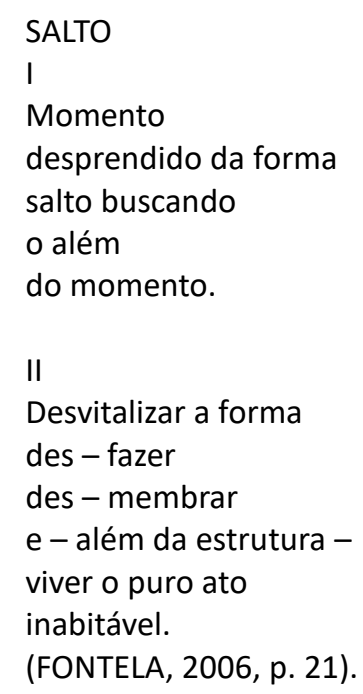

O próprio título do livro, Transposição, já nos dá pequeno indício de uma conversa entre Fontela, Benjamin e Derrida, ao apontar para a tarefa messiânica do tradutor: a reunião dos cacos da Schebira, uma tarefa utópica de reunião da multiplicidade.

A partir do verbo alemão übersetzen, temos dois significados distintos, mas conexos: o primeiro é, em seu uso mais comum, traduzir, configurando-se assim em sua forma, pela partícula não separável über [sobre]. O segundo pode adquirir a significação de transpor, na forma em que a partícula über e o verbo setzen [colocar, pôr, há várias possibilidades] se separam. Já no século XV, o tradutor e humanista italiano Leonardo Bruni apresenta um novo significado para o vocábulo traduzir traducere, tomando-o por transposição semântica de termos ou textos de uma língua para outra, mudando a significação anterior da tradição latina em que traduzir era entendido como uma inserção física na língua de uma palavra estrangeira.

Essa mesma transposição surge nos poemas de Orides Fontela radicalizando o lúdico jogo de transposições, pueris: jogos des-concertantes e disseminatórios como bem vemos armados no poema "Ludismo",

As peças são outros jogos:

construiremos outro segredo.

Os cacos são outros reais antes ocultos pela forma

e o jogo estraçalhado 
se multiplica ao infinito

e é mais real que a integridade: mais lúcido.

(FONTELA, p. 2006, p. 18).

O salto nos possibilita a desconstrução da estrutura, centro, origem enquanto gênese [Herkunft]. Não se trata da simples apropriação de um original pleno, sagrado, mas sim, de um jogo profanador da estrutura binária e inabalável, em que estranho e próprio se contaminam em um lúdico jogo de mútua hospitalidade. Assim, dá-se o jogo de uma possibilidade utópica em seu Spielraum, como escreve Orides Fontela: "viver o puro ato / inabitável."

A hospitalidade, segundo Derrida, é vista como uma reciprocidade de responsabilidade entre o estranho-intruso [original] e o próprio [tradução], ao enfocar o florescimento das relações provenientes desse encontro e do contato estabelecido entre aquele que a princípio nos parece diferente, incomum por sua própria natureza. Ilustrando seu pensamento a partir da ética da alteridade de Emmanuel Levinas, ponto de partida e chegada derridiana, para pensarmos na hospitalidade incondicional, Derrida dirá:

\begin{abstract}
A hospitalidade não é apenas receber o que se pode receber. Levinas diz em algum lugar que o sujeito é um anfitrião que deve acolher o infinito além de sua capacidade de receber. Acolher além de sua capacidade de recepção: isso significa que devo receber ou que recebo no lugar onde não posso receber, no lugar onde a vinda do outro me excede, parece maior do que minha casa. ${ }^{4}$ (DERRIDA, 2011, p. 97).
\end{abstract}

Circular nesta inscrição do idioma da hospitalidade incondicional, aquela a desvelarse na entrega, é doar-se ao outro em sua estranheza - Fremdartigkeit - ou seja, livre de qualquer apreensão pré-concebida. De um ponto de vista, o estranho se torna próximo por seu contato com o próprio, pelo nome que carrega do pai. Mas o que interessa a Derrida não é aquele hóspede estranho que afirma claramente seu nome, a marca paterna, sua origem, e sim aquele que impõe o que chamará de hospitalidade incondicional, ou seja, aquele para quem o hospedeiro abrirá a sua casa sem exigir nada em troca, nem mesmo seu nome, num ato de entrega e confiança utópicas.

Receber o estranho significa, certamente, aceitar sua intrusão. Jean-Luc Nancy dirá que "O intruso se introduz à força, por surpresa ou por astúcia; em todo caso, sem direito e sem ter sido admitido de antemão. É indispensável que no estrangeiro haja algo do intruso, pois sem ele perde sua estranheza." ${ }^{5}(2006$, p. 11). O estranho não se apresenta, como

\footnotetext{
${ }^{4}$ L'hospitalité ne consiste pas simplement à recevoir ce qu'on est capable de recevoir. Lévinas dit quelque part que le sujet est un hôte qui doit accueillir l'infini au-delà de sa capacité d'accueil. Accueillir au-delà de sa capacité d'accueil: cela veut dire que je dois recevoir ou que je reçois là ou je ne peux pas recevoir, là ou la venue de l'autre m'excède, paraît plus grande que ma maison. (Tradução minha)

${ }^{5}$ El intruso se introduce por fuerza, por sorpresa o por astucia; en todo caso, sin derecho y sin haber sido admitido de antemano. Es indispensable que en el extranjero haya algo del intruso, pues sin ello pierde su ajenidad.
} 
essência, em oposição ao próprio, mas ambos adquirem suas significações nas decisões e gestos políticos do tradutor.

Nancy opera, através de uma sensível metáfora para seu conceito de intruso, com uma narrativa que transborda a compreensão a partir do próprio corpo enfermo - o trabalho de um coração que finda em si mesmo - e o estranho, segundo sua experiência pessoal de transplante cardíaco. ${ }^{6}$

O corpo, ou aquilo que queremos entender por próprio, é invadido pelo estranho, que o penetra, abrindo-se à sua possibilidade de hospitalidade incondicional. $\mathrm{O}$ estranho adentra o próprio do corpo que lhe oferece sua casa e o aceita como condição urgente de sobrevivência. Note-se, saliento, aqui, a sobrevivência de ambos: não há vida para o corpo sem um coração, tampouco para o coração sem um corpo.

Claro, há nos transplantados o temor da rejeição, o órgão muitas vezes é expulso, não consegue hospedagem em novo território. Esse encontro com o fortuito, com o impremeditado, sobretudo com um estranho que pede asilo, mas que deseja se juntar ao próprio e fazer dele sua casa, abrindo-o para sua própria desterritorialização, é a pervivência de corpo e intruso [fortleben] que buscam resistir à sua falência.

Aqui, o ganho de pervivência é mútuo: estranho e tradução se lançam conjuntamente no jogo de sobrevivência e renovação, contato e contaminação para ambos. Estranho e próprio se transformam, sobrevivem e se modificam: "O intruso está em mim e me converto em estrangeiro para mim mesmo."7 (NANCY, 2006, p.32).

\section{A comunidade por vir de Kafka e Benjamin: a utopia do resto}

Em seu texto, "Frank Kafka: a propósito do décimo aniversário de sua morte", Benjamin menciona que, na obra de Franz Kafka, O processo, os acusados são seus personagens mais belos, exatamente por não contarem com esperança. Benjamin cita brevemente o fragmento de um diálogo existente entre Kafka e Max Brod, narrado pelo próprio Brod:

\footnotetext{
Recordo-me [Max Brod] de uma conversa com Kafka, cujo ponto de partida foi a Europa contemporânea e a decadência da humanidade. Somos, disse ele, pensamentos niilistas, pensamentos suicidas que surgem na cabeça de Deus. Essa frase evocou em mim a princípio a visão gnóstica de mundo: Deus como um demiurgo perverso, e o mundo como seu pecado original. Oh não, disse ele, nosso mundo é apenas um mau humor de Deus, um dos seus maus dias. Existiria então esperanças, fora desse mundo de aparências que conhecemos? Ele riu: há esperança suficiente, esperança infinita - mas não para nós. (BENJAMIN, 1985, p. 141-142).
}

\footnotetext{
${ }^{6}$ Em 1992, Jean-Luc Nancy foi operado com o coração aberto e recebeu um transplante cardíaco. Essa operação foi seguida por complicações que Ihe comprometem a saúde até hoje.

${ }^{7}$ El intruso está en mí, y me convierto en extranjero para mí mismo.
} 
Benjamin não menciona esse curto trecho para declarar Kafka um escritor da desesperança. Ao contrário, nas páginas que seguem, pensa em sua escrita mística como uma operação de passagem da potência ao ato: eticamente política e politicamente ética. $E$ se há esperança suficiente, esperança infinita, existe, simultaneamente, ainda que ela não nos seja dada, uma possibilidade utópica de alcançá-la, como nos diz Giorgio Agamben:

O aforismo kafkiano, segundo o qual há salvação, mas não para nós, encontra aqui o seu único sentido. Como resto, nós, os viventes que restam en tō nyn kairó, tornamos possível a salvação, somos a sua primícia [...], estamos, por assim dizer, já salvos; mas exatamente por isso, não é enquanto resto que seremos salvos. O resto messiânico excede irremediavelmente o todo escatológico, ele é o insalvável que torna possível a salvação. (AGAMBEN, 2016, p. 73).

Veja-se o emprego da expressão do tempo de agora en tō nyn kairố, que, de acordo com Agamben, é a sentença que caracteriza o tempo messiânico, lida nas Cartas aos Romanos de Paulo. Em sua essencialidade necessária, o conceito de resto nos oferece uma promessa de reformulação das noções categoriais de povo e democracia: "E esse resto é a figura ou a consistência que o povo ganha na instância decisiva - e, como tal, ele é o único sujeito político real." (AGAMBEN, 2016, p. 73) O resto é, então, a proposta utópica de Benjamin, para quem a fraca força messiânica se dá em seu Jetztzeit, ou o tempo-de-agora. Nessa intempestividade súbita do tempo kairológico [en tō nyn kairố] - o tempo das intensidades - é gestada a parte-dos-sem-parte [segundo definição de Jacques Rancière ${ }^{8}$ ] nós os viventes -, em termos marxianos, uma utópica sociedade por vir.

Agamben, no livro $O$ tempo que resta, resgata uma série de decisões tradutórias na história da interpretação dos textos de Paulo, que eliminaram os comentários de todo seu conteúdo messiânico. O termo klētós, oriundo do verbo kaléo, "chamar", possui como significado "chamado". Já na Carta aos Coríntios, Paulo se utiliza desse termo para definir a vida messiânica, em especial na forma derivada do verbo kaléó: klēsis [vocação, chamado]. Agamben não busca apenas recuperar esse sentido messiânico original, mas também analisa a partir de Max Weber sua tradução luterana em alemão para o termo Beruf [vocação, profissão], chegando a conclusão que, para Weber, o espírito capitalista é uma secularização da ética puritana de profissão/chamado [Beruf].

A vocação messiânica torna-se ambígua, significando, ao mesmo tempo, vocação messiânica [klēsis] e profissão profana [Beruf]. Agamben cita, ainda, o historiador grego Dionísio de Halicarnasso que apresenta a derivação do termo latino classis [uma indicação de parte dos cidadãos chamados às armas] a partir do grego klēsis. Aqui é desvelado, possivelmente, o indício demonstrado por Agamben entre a klēsis messiânica e o pensamento marxiano. Para Marx, O Stand enfrenta a fratura provocada pela burguesia que

\footnotetext{
${ }^{8}$ Michel Foucault, entrevistado por Jacques Rancière, em 1977 "fala da plebe como elemento inatribuível e absolutamente irredutível às relações de poder". (FOUCAULT, apud AGAMBEN, 2016, p. 73). Anos mais tarde, o próprio Rancière reformulará essa noção de povo a partir da ideia de parte dos sem parte, portadora de uma injustiça que torna de democracia como "comunidade do litígio".
} 
os dissolve em Klasse, provocando a cisão entre o indivíduo e sua figura social, esvaziado de significado. A Klasse ou proletariado:

encarna em si essa mesma fratura e coloca, por assim dizer, a nu a contingência de toda figura e de toda condição social é também a única que pode abolir a mesma divisão em classes para emancipar, ao mesmo tempo, a si própria e toda a sociedade. (AGAMBEN, 1016, p. 43).

Alguns fragmentos preparatórios das "Teses sobre o conceito de história" de Benjamin operam como suplementos dos mais diversos. Dado seu caráter heterogêneo, podem apresentar diversamente maior e, igualmente, menor aproximação do texto final. Como podemos observar no fragmento XVIla, trecho retirado do manuscrito 1098 do arquivo Walter Benjamin, Benjamin identifica claramente o elo para Marx entre o tempo messiânico e a ideia de sociedade sem classes [klēsis]:

\footnotetext{
Marx secularizou na ideia da sociedade sem classes a ideia do tempo messiânico. $E$ a ideia foi boa. A desgraça começa quando a social-democracia resolveu elevar essa ideia à condição de "ideal". [...] Se a sociedade sem classes começou por ser definida como tarefa infinita, o tempo vazio e homogêneo transforma-se, por assim dizer, numa antecâmara onde se podia esperar mais ou menos tranquilamente pela entrada da situação revolucionária [...] (A sociedade sem classes não é o objetivo final do progresso na história, mas sim a sua interrupção, tantas vezes fracassada e por fim concretizada). (BENJAMIN, 2012, p. 177).
}

Dessa forma, lido através da exposição agambeniana do conceito de resto messiânico, juntamente ao sentido apontado por Benjamin a respeito da secularização desse mesmo tempo messiânico em Marx, a comunidade messiânica [ekklesia], a parte-dos-sem-parte, é o próprio povo [nós os viventes]: responsável, constitutivamente, de assinalar os limites das relações de poder, tornando possível o salto dialético que viabilizará a revolução proposta por Marx, liberta, no entanto, do tempo homogêneo e vazio da história, ideia tão defendida nas "Teses sobre o conceito de história" de Benjamin.

A esfera do messiânico para Walter Benjamin esquiva-se, inevitavelmente, do viés meramente religioso, seu esforço constante é o de fazer transbordar um pensamento que frature as noções delimitadas de política, estética, magia e linguagem. A leitura através da proposição do resto e sua revisão das categorias de povo e classe, a partir das Cartas de Paulo, elaborada por Giorgio Agamben, aproxima-se do ponto em que o messianismo paulino se conjuga numa constelação remetente não somente ao sentido religioso, mas, também, ao político, histórico e linguístico, algo muito próximo do método benjaminiano: intensificar os limiares de contato entre o messiânico e profano, o mágico e técnico, o estético e político.

As parábolas enigmáticas de Kafka [cujas alegorias já estão para sempre dissipadas no real] trazem, afinal, um mistério de acordo com essa possibilidade utópica, da ordem do resto. Nas palavras de Kafka, retiradas do breve trecho da narrativa intitulada "Sobre a 
questão das leis": "virá um tempo no qual - de certo modo com um suspiro - a tradição e o seu estudo chegarão ao ponto final, que tudo terá ficado claro, que a lei pertencerá ao povo [grifo meu] e que a nobreza desaparecerá." (KAFKA, 2002, p. 125). De fato, o messias coincide exatamente com o espaço de conflito da lei vigente. Há um impasse entre dois aspectos destacados pelos estudiosos da cabala: A Torá de Beriah, ou a lei do mundo não redimido, do tempo da criação, e a Torá de Atzilut, a lei anterior à criação e que deve ser restaurada pelo messias.

Além de partilhar o desejo de uma comunidade por vir e da inoperância da lei, Kafka e Benjamin aguardam pela faísca revolucionária latente, pulsante, no tempo-de-aqui-agora. 0 messianismo judaico representa, para ambos, o por vir de uma nova espacialidade do presente suspenso, a saber, o da redenção, que por sua vez é discrepante da lei vigente, ou seja, da tradição.

É importante lembrarmos, ainda, que um dos primeiros textos de Benjamin, intitulado "Diálogo sobre a religiosidade do nosso tempo", já apresentava seu engajamento em torno da defesa de uma comunidade por vir indissociável de uma religiosidade vindoura. Essa fase intelectual e ativista de Benjamin foi influenciada, sobretudo por Gustav Wyneken e seu projeto de reforma pedagógica através da Comunidade Escolar Livre [Freie Schulgemeinde] em Wickersdorf. Nas palavras de Benjamin:

Aos poucos, uma nova geração terá ousadia de voltar e examinar a si própria, e não só por meio de seus artistas. Ela reconhecerá a pressão e a inverdade que agora nos coagem. Ela reconhecerá o dualismo de moralidade social e personalidade. Dessa necessidade brotará uma religião. (BENJAMIN, 2013, p. 41).

Afora o anseio por uma comunidade vindoura, surge o apelo por uma tarefa messiânica dessa mesma comunidade, indissociável da linguagem enquanto experimentum, ou Medium - Spielraum - puro da história, como aponta Maria João Cantinho:

Aliam-se a este ideal de comunidade a ideia de uma tarefa messiânica que devia ser levada a cabo, tanto no plano da história e da experiência, como da própria linguagem, sem a qual a actualização do "reino messiânico", como ele o define no seu texto de 1914/15, A Vida dos Estudantes, jamais poderia cumprir-se. (CANTINHO, 2011, p. 58).

No texto de 1916 intitulado "Sobre a linguagem em geral e sobre a linguagem do homem", Benjamin delineia, já precocemente, sua teoria da tradução ao pensar a linguagem [entenda-se aqui, da mesma forma, a tradução] como Medium [espaço, lugar em que se dá a experiência, mas também o jogo, a história] no lugar de sua instrumentalização, ou a linguagem como um Mittel [meio, através de] que possibilita a comunicação. A segunda idealização é designada por Benjamin uma concepção burguesa da linguagem [bürgerliche Auffassung der Sprache], incongruente e de caráter vazio; ao contrário da primeira, a linguagem como Medium representa uma metafísica da linguagem que "não conhece nem 
meio, nem objeto, nem destinatário da comunicação." (BENJAMIN, 2011, p. 55). Irving Wohlfarth acrescenta, em seu texto "O meio da tradução" [Das Medium der Übersetzung], suas considerações a respeito da concepção de linguagem de Benjamin, tradução e messianismo: "À luz dessa interpretação teológica linguística da história do Gênesis, a concepção "burguesa" de linguagem e a concepção "convencional" de tradução podem ser identificadas como duas consequências fatais da queda do homem [Sündenfall]." (WOHLFARTH, 2001, p. 89) Os conceitos de tradução e sua possibilidade utópica não são somente noções linguísticas, elas corroboram um pensamento que se dirá, dele mesmo, do horizonte da revelação e redenção, seu alicerce se dá na suspensão da história, na linguagem enquanto Medium, ou Spielraum.

Os chamados textos de juventude operam como pilar das considerações de Benjamin acerca da tarefa do tradutor de 1923: a utópica atividade messiânica que conduzirá essa mesma parte-dos-sem-parte até a língua pura enquanto Medium de uma experiência não burguesa $^{10}$ e instrumentalizada na história. Não por acaso, a tradução seria a via de mão única para pensarmos a comunidade por vir notadamente porque nos impõe a asseveração de uma falta. A tarefa do tradutor não representa uma volta à única língua adâmica, mas se dá em outra direção, ela remonta à multiplicação e à compreensão utópica de todas as línguas, sua ética é potência do olhar para uma política da democracia por vir.

\section{Referências}

AGAMBEN, Giorgio. Elogio da profanação. In: AGAMBEN, Giorgio. Profanações. Tradução: Selvino J. Assmann. São Paulo: Boitempo, 2007.

AGAMBEN, Giorgio. O tempo que resta: um comentário à Carta aos Romanos. Tradução: Davi Pessoa e Claudio Oliveira. Belo Horizonte: Autêntica, 2016.

BENJAMIN, Walter. A tarefa do tradutor. In: BENJAMIN, Walter. Escritos sobre mito $e$ linguagem. Tradução Susana Kampff Lages. São Paulo: Editora 34, 2011.

BENJAMIN, Walter. Sobre a linguagem em geral e sobre a linguagem do homem. In: BENJAMIN, Walter. Escritos sobre mito e linguagem. Tradução: Susana Kampff Lages. São Paulo: Editora 34, 2011.

BENJAMIN, Walter. O anjo da história. Tradução: João Barrento. Belo Horizonte: Autêntica, 2012.

BENJAMIN, Walter. Franz Kafka - A propósito do décimo aniversário de sua morte. Tradução: Sérgio Paulo Rouanet. In: BENJAMIN, Walter. Magia e técnica, arte e política. São Paulo: Brasiliense, 1985.

\footnotetext{
${ }^{9}$ Im Lichte dieser sprachtheologischen Deutung der Genesis-Geschichte lassen sich die "bürgerliche" Aufffasung der Sprache und die "herkömmliche" Aufffasung der Übersetzung als zwei fatale Folgen des Sündenfalls identifizieren.

${ }^{10} \mathrm{O}$ conceito de Erfahrung (experiência) perpassa toda a sua obra: inicialmente através do texto de juventude, escrito em 1913, intitulado Erfahrung, em que Benjamin aponta com críticas à a experiência do adulto - uma experiência supostamente superior - em detrimento da experiência revolucionária que partiria dessa comunidade desejada por Walter Benjamin.
} 
BENJAMIN, Walter. Diálogo sobre a religiosidade do nosso tempo. In: BENJAMIN, Walter. $O$ Capitalismo como Religião. Tradução: Nélio Schneider. São Paulo: Boitempo, 2013

CANTINHO, Maria João. A língua que advirá: o tempo da comunidade. Cadernos Walter Benjamin. Fortaleza, v.6, jan/jul 2011. Disponível em: http://www.gewebe.com.br/pdf/cad06/texto 04.pdf Acesso em: 04 abr. 2020.

DERRIDA, Jacques. Torres de Babel. Tradução: Junia Barreto. Belo Horizonte: Ed. UFMG, 2002.

DERRIDA, Jacques. Dire L'événement, est-ce possible? Séminaire de Montréal, pour Jacques Derrida. Paris: I'Harmattan, 2011.

FONTELA, Orides. Poesia reunida: 1969-1996. São Paulo: Cosac Naify; Rio de Janeiro: 7 Letras, 2006.

KAFKA, Franz. Sobre a questão das leis. In: KAFKA, Franz. Narrativas do espólio. Tradução: Modesto Carone. São Paulo: Companhia das Letras, 2002.

NANCY, Jean-Luc. El intruso. Tradução: Margarita Martínez. Buenos Aires: Amorrortu, 2006.

WOHLFARTH, Irving. Das Medium der Übersetzung. In: HART-NIBBRIG, Christiaan L. (org.). Übersetzen: Walter Benjamin. Frankfurt am Main: Suhrkamp, 2001.

Recebido em: $19 / 10 / 2020$

Aceito em: $12 / 11 / 2020$ 